\title{
Inhibition of attended processing during saccadic eye movements
}

\author{
JAMES R. BROCKMOLE \\ University of Illinois at Urbana-Champaign, Champaign, Illinois \\ LAURA A. CARLSON \\ University of Notre Dame, Notre Dame, Indiana \\ and \\ DAVID E. IRWIN \\ University of Illinois at Urbana-Champaign, Champaign, Illinois
}

\begin{abstract}
People are unable to perform some, but not all, cognitive tasks while moving their eyes. A possible common denominator among disrupted processes is the use of attention. The present research proposes and tests an attentional suppression hypothesis to evaluate this claim. This hypothesis states that because attention is obligatorily allocated to a to-be-fixated location prior to the onset of a saccade, during saccadic events attentional resources are unavailable to direct processing associated with higher order cognitive tasks. Subjects were engaged in a task that combined saccades and shifts of attention across global and local levels of hierarchicalfigures. When the eyes did not move, this shift took place between stimulus presentations. When saccadesintervened between the stimuli, the global-local shifts of attention were interrupted, suggesting that saccades suppress cognitive processes requiring attention.
\end{abstract}

Imagine that you live in a world illuminated only by the constant flicker of a strobe light. Each time the light flashes you are able to perceive detailed visual information from the environment. During moments of darkness, however, virtually no visual perception takes place. The result is a fragmented representation of the world around us. Although this imagined world seems highly bizarre, the example serves as an illustration of what our brains confront each second of every waking day as we view our visual world. In order to examine our environment, we must move our eyes from one object of interest to another. The eye movements that take us from one point of fixation to another are called saccades. They occur about every $250-300 \mathrm{msec}$ and generally have a duration of between 30 and $100 \mathrm{msec}$, depending on the distance the movement covers (Rayner, 1978, 1998). A consequence of saccadic eye movements is that visual sensitivity is

Portions of this research constituted an honors thesis by J.R.B. at the University of Notre Dame. The research was supported by a grant from the Institute for Scholarship in the Liberal Arts in the College of Arts and Letters at the University of Notre Dame and an NSF Graduate Research Fellowship to J.R.B., NSF Grant SBR-97-27638 to L.A.C., and NSF Grant SBR-96-15988 to D.E.I. We thank Gary Dell, Bradley Gibson, John Henderson, Gordon Logan, Lynn Robertson, Keith Rayner, Frances Wang, and two anonymous reviewers for their insightful comments at various stages of this research. We also thank Wainani Au, Melissa Byerly, Eric Covey, Magda Krol, and Todd Warapius for their help with data collection. Address all correspondence concerning this article to J. R. Brockmole, Department of Psychology, University of Illinois, 603 E. Daniel St., Champaign, IL 61820 (e-mail: jbrockmo@ s.psych.uiuc.edu). greatly reduced during the movement, thereby confining the vast majority of visual perception to the fixations between the saccades. This phenomenon is known as saccadic suppression (Matin, 1974; Volkmann, 1986; Zuber, Crider, \& Stark, 1964; Zuber \& Stark, 1966). Thus, the input for visual perception is like a world illuminated by a strobe light, fragmented and discontinuous. Despite this, our phenomenological experience of the world is a stable and continuous whole.

In the past, researchers have proposed the existence of a transsaccadic memory store that maintains and accrues information from individual fixations across saccades as a mechanism for overcoming the effects of saccadic suppression (Breitmeyer, Kropfl, \& Julesz, 1982; McConkie $\&$ Rayner, 1976). Rather than finding evidence for such a mechanism, however, researchers have found that little information is actually accumulated across saccades (Bridgeman \& Mayer, 1983; Henderson, 1997; Irwin, Brown, \& Sun, 1988; Irwin, Yantis, \& Jonides, 1983; McConkie, 1991; O'Regan \& Levy-Schoen, 1983; Rayner \& Pollatsek, 1983), although some limited visual information, such as pattern structure and spatial relationships, is remembered from fixation to fixation (e.g., Carlson-Radvansky, 1999; Carlson-Radvansky \& Irwin, 1995; Irwin, 1991, 1992; Pollatsek \& Rayner, 1992). Indeed, Irwin $(1992,1996)$ suggested that the capacity of transsaccadic memory is between three and six itemsa very small part of an actual visual scene (see, however, Hollingworth \& Henderson, 2002). What items get remembered across saccades is determined by attention. In 
preparation for a voluntary saccade, attention obligatorily and involuntarily precedes the movement of the eyes to the future saccade target (Deubel \& Schneider, 1996; Hoffman \& Subramaniam, 1995; Irwin \& Gordon, 1998; Kowler, Anderson, Dosher, \& Blaser, 1995; Rayner, McConkie, \& Ehrlich, 1978; Shepherd, Findlay, \& Hockey, 1986). ${ }^{1}$ This focus of attention on a particular aspect of a visual scene (the target area of the next fixation) just prior to the saccade seems to enable the information in that region to be remembered across the saccade, whereas information from other areas is less likely to be retained (e.g., Currie, McConkie, Carlson-Radvansky, \& Irwin, 2000; Henderson \& Hollingworth, 1999; Irwin \& Gordon, 1998).

Recently, some researchers have proposed that the allocation of attention to saccade targets not only places limitations on what is remembered across saccades, but is also the root cause of a recently explored phenomenon called cognitive suppression (so named by Irwin \& CarlsonRadvansky, 1996). Cognitive suppression refers to the interference or inhibition of higher order cognitive functions by saccadic eye movements. The first reports of saccades' interfering with cognitive tasks showed that when subjects had to overcome the effects of a pattern mask on visual stimuli in order to identify them, the stimulus resolution, or "clean-up," occurred either before or after, but not during, the saccade (Sanders \& Houtmans, 1985; Sanders \& Rath, 1991). In addition, Matin, Shao, and Boff (1993) demonstrated that processing time in a counting task when saccades were required to obtain information increased by over twice the magnitude of the saccade durations alone (saccade duration was approximately $40-45 \mathrm{msec}$, processing time increased approximately $100 \mathrm{msec}$ per saccade). This suggested that the saccades interfered with central processing. Van Duren (1993) also showed that memory search in a Sternberg memory-scanning task is at least partially suspended during saccades (see Irwin, 1998, for a commentary). And most recently, Irwin and Carlson-Radvansky (1996) and Irwin and Brockmole (2000) argued that the ability to mentally rotate figures during saccades is completely suppressed.

To date, the cause of cognitive suppression is unknown, although there has been some recent speculation. Irwin (1998) noticed that the cognitive processes that are suppressed by saccades require attention, whereas automatic processes, such as pathway priming (Irwin, CarlsonRadvansky, \& Andrews, 1995) and lexical processing (Irwin, 1998), are not inhibited by saccadic eye movements. He suggested that this difference may be important to understanding the nature and causes of cognitive suppression. In this paper, we propose and empirically test an attentional suppression hypothesis in order to evaluate Irwin's observations.

As was noted earlier, saccades draw upon attentional resources in that, prior to the onset of a saccade, attention is allocated to the to-be-fixated location in an obligatory and involuntary fashion. According to the atten- tional suppression hypothesis, when attention is engaged by saccadic planning and execution, it is unavailable to direct processing associated with deliberative cognitive tasks. As a result, attention-demanding cognitive processes are suppressed during the saccade, whereas automatic processes that do not require attention are unaffected.

We chose to assess this hypothesis by engaging subjects in a task that required not only the involuntary attention shifts demanded by saccades (i.e., attention movements from one locus of fixation to another), but also volitional shifts of attention associated with the alternate processing of global and local forms of hierarchical figures.

\section{GLOBAL-LOCAL JUDGMENTS AND VOLITIONAL ATTENTION}

Figure 1 illustrates stimuli (taken from Kimchi \& Palmer, 1985) that can be described in two ways. First, each possesses a global form of either a square (A and C) or a rectangle (B and $\mathrm{D})$. Second, these global forms are constructed from smaller (local) elements that are also either squares (A and B) or rectangles (C and D). These figures are said to be hierarchical because one level of description (global) is built from another, equally distinct level (local; Navon, 1977). The relationship between the global and the local levels in each figure can be congruent (A and D), where the global form and local elements are identical in shape, or incongruent (B and $\mathrm{C}$ ), where the global form is not the same shape as the local elements. Past research on global precedence suggests that one must attend to either the local or the global level in order to recognize the shape that exists at that level (e.g., Kinchla, Solis-Marcias, \& Hoffman, 1983; Navon, 1977; Pomerantz, 1983). Thus, a shift of attention is required whenever subjects must alternate between global and local judgments of form (e.g., Robertson, 1996; Robertson, Egly, Lamb, \& Kerth, 1993; Robertson \& Lamb, 1991; Ward, 1982).

Ward (1982) used hierarchical stimuli similar to those shown in Figure 1 to assess the impact of shifts of attention on processing global and local information. ${ }^{2}$ For our

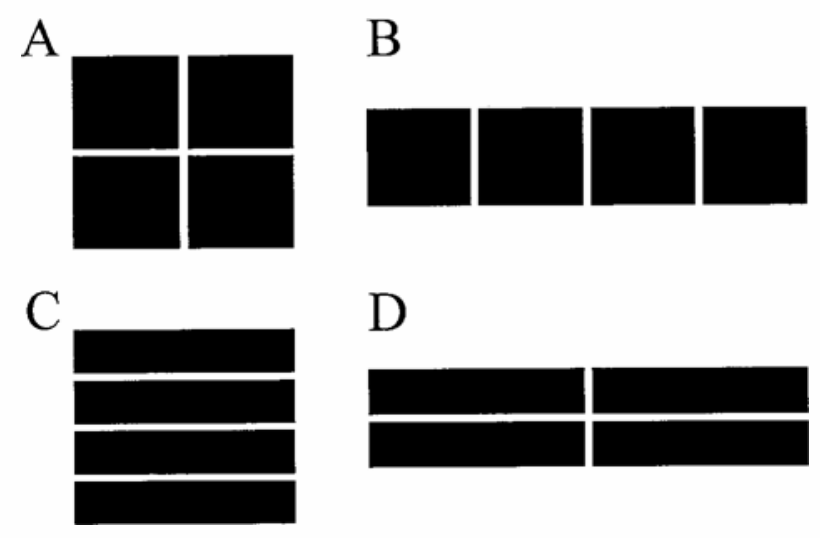

Figure 1. The stimuli used in Experiments 1 and 2. 
purpose, we are particularly interested in the cost (in terms of response times) of this attentional shift. Ward presented subjects with a series of hierarchical figures, each of which required a speeded classification response of shape (i.e., square or rectangle) on the basis of either the figure's global form or local elements. Three conditions were created. First, responses to all trials were global identifications (GGGG ...). Second, responses to all trials were local identifications (LLLL ...). Third, responses alternated between global and local identifications (GLGL ...). This last condition incorporated a shift of attention between levels of processing from one trial to the next.

Following data collection, Ward (1982) divided the streams of stimuli into pairs in order to look for an effect on response time for the second trial as a function of the type of processing that occurred on the first trial. Although accuracy was generally at ceiling, Ward found that shifting attention from one level of processing to another was costly, with GL trials slower than LL trials and LG trials slower than GG trials. This pattern of data has been replicated more recently by Robertson (1996) and Robertson, Egly, et al. (1993).

Our primary interest in the research reported in the present paper is to determine whether saccades interfere with the shifts of attention required for processing global versus local forms. The attentional suppression hypothesis predicts that interference should occur. Before we could assess this hypothesis, however, an additional investigation of the characteristics of global-local processing was required. Although it is clear that global-local shifts of attention are time consuming and impose costs with respect to reaction times, some properties of this shift cost are unclear-namely, when does the shift occur (during or between stimulus presentations) and how much time does this shift require? Answers to these questions are critical to the design and analysis of an experiment aimed at assessing whether global-local shifts of attention occur during saccades. Accordingly, before we turn to our experiment that directly assesses the attentional suppression hypothesis (Experiment 2), we first describe an experiment whose aim was to characterize the temporal aspects of global-local shifts of attention.

\section{EXPERIMENT 1}

Ward's (1982) procedure provides a powerful way to observe the costs of shifting attention across levels of hierarchical figures. However, it is unable to assess two important questions: When do the global-local shifts of attention take place, and how much time do the shifts require? In order to address these questions, a simple modification to Ward's procedure was made. Rather than present streams of stimuli, only to later divide them into pairs for analysis, within a single trial two hierarchical stimuli (Figure 1) were sequentially presented as a pair. Response times to each individual stimulus were measured from its onset; throughout this paper, we refer to the first and second stimulus response times within a trial as RT1 and RT2, respectively. On all trials, the subjects were instructed to attend to the global dimension of the first figure and the local dimension of the second, or vice versa. Thus, every trial involved a time-consuming shift of attention. Within an individual trial, the elapsed time between stimulus presentations was manipulated by varying the interval between the first response and the presentation of the second stimulus (RSI). RSIs ranged from 0 to $825 \mathrm{msec}$ by intervals of $75 \mathrm{msec}$. By observing the pattern of response times as a function of RSI, not only could the costs of shifting attention across levels of the figures be observed, but also determination of when the shift took place (i.e., between stimulus presentations?) and its time course could be estimated.

If, in anticipation of the second stimulus, the subjects begin to shift their attention prior to the presentation of the second stimulus, the shift of attention occurs, at least in part, between stimulus presentations (during the RSI). This would yield a general decrease in RT2 as RSI increases. At early RSIs, the shift does not have time to be completed prior to the presentation of the second stimulus (when RT2 starts to be timed). Therefore, RT2 will absorb some of the shift time. However, as RSI increases, a greater portion of the necessary shift is completed prior to the presentation of the second stimulus. This results in a decrease in RT2. Eventually, RT2 will no longer decrease by RSI, because the shift is entirely completed prior to the presentation of the second stimulus. At this point, the RT2 curve will asymptote. The point at which this occurs provides a measure of how long the shift of attention takes to complete. In contrast, if the shift of attention does not occur between stimulus presentations but, rather, is stimulus bound, no effect of RSI will be observed. This pattern of data would be expected regardless of whether the global-local shift of attention is anticipatory or delayed (i.e., the shift may occur entirely within RT1, entirely within RT2, or partially within both).

\section{Method}

\section{Subjects}

Thirty-four undergraduates at the University of Notre Dame participated after providing informed consent. The subjects were compensated with partial course credit. Two additional subjects participated but were excluded from the analyses owing to missing data as a result of inaccuracy or withdrawal. All were naive with respect to the experimental hypotheses.

\section{Stimuli}

The stimuli were adapted from Kimchi and Palmer (1985, Experiments 3 and 4; see Figure 1). The stimuli were created by orthogonally combining squares and rectangles to create four figures, each possessing a global form (square or rectangle) composed of four local elements (squares or rectangles).

The stimuli were presented on a computer screen. During the experiment, the subjects were seated $36 \mathrm{~cm}$ from the display monitor. At this viewing distance, the total display subtended $53^{\circ}$ of visual angle horizontally and $40^{\circ}$ vertically. Figures $1 \mathrm{~A}$ and $1 \mathrm{C}$ (global form is a square) subtended $1.25^{\circ}$ horizontally and vertically. Fig- 
ures $1 \mathrm{~B}$ and $1 \mathrm{D}$ (global form is a rectangle) subtended $2.57^{\circ}$ horizontally and $0.56^{\circ}$ vertically. In terms of local elements, each square subtended $0.56^{\circ}$ horizontally and vertically, and each rectangle subtended $1.25^{\circ}$ horizontally and $0.23^{\circ}$ vertically. The stimuli were presented in SVGA-LO mode $(640 \times 200)$. The display background was light gray, and the figures were dark blue.

\section{Apparatus}

The stimuli were presented at a refresh rate of $72 \mathrm{~Hz}$ on an NEC MultiSync 4FGe monitor. A Dell OptiPlex GXpro microcomputer controlled stimulus presentation with an SVGA adapter. The subjects made responses to all stimuli by pressing one of two keys on a keyboard.

\section{Design}

The four figures were combined into all 16 possible pairs. Each trial consisted of a pair of stimuli presented sequentially in the center of the screen. For each stimulus, the subjects identif ied the global form or local elements by indicating square or rectangle. The RSI ranged from 0 to $825 \mathrm{msec}$ by intervals of $75 \mathrm{msec}$. Each stimulus combination (16) was crossed with each RSI(12). Using a repetition factor of 2 , each subject completed a total of 384 trials in a different random order. Response times and accuracy for the individual stimuli within a trial were recorded.

The subjects were randomly assigned to one of two instruction conditions. Seventeen subjects identified the global shape of the first stimulus and the local shape of the second, whereas the other 17 subjects identified the local shape of the first stimulus and the global shape of the second.

\section{Procedure}

At the beginning of each trial, a dark blue "+" sign (subtending $0.2^{\circ}$ horizontally and $0.4^{\circ}$ vertically) appeared in the center of the screen for $1,500 \mathrm{msec}$, whereupon the first stimulus was presented for $300 \mathrm{msec}$. The subjects made a response to this stimulus by pressing one of two keys on a keyboard marked with either an "S" or an "R," signifying square and rectangle, respectively. Then, the fixation cross appeared for the duration of the RSI for that trial. The second stimulus was then presented for $300 \mathrm{msec}$, and the response was collected. The subjects were told to make their responses as quickly and as accurately as possible. Following the response to the second stimulus, a message was displayed to the subject, telling them to press a key to begin the next trial.

\section{Results and Discussion}

The analyses focused on trials in which both stimuli were incongruent (i.e., Figure 1, panels B and C). Such trials are the only ones in which responses can be interpreted with respect to instructions. For example, given a congruent stimulus (e.g., Figure 1, panel A), a correct response (e.g., square) could be given regardless of the level that was actually attended. Therefore, there is no way to verify that the subjects were processing the instructed level. In addition, prior to data analysis, trials were excluded if either Response 1 or Response 2 was incorrect. For global-to-local (GL) trials, an incorrect response to the first stimulus occurred on $8 \%$ of the trials, and an incorrect response to the second stimulus occurred on $6 \%$ of the trials. A combination occurred on $1 \%$ of the trials. For local-to-global (LG) trials, an incorrect response to the first stimulus occurred on $12 \%$ of the trials, and an incorrect response to the second stim- ulus occurred on $18 \%$ of the trials. A combination occurred on $7 \%$ of the trials. In sum, $13 \%$ of the GL and $23 \%$ of the LG trials were excluded from the analyses.

Separate 2 (direction of shift) $\times 12$ (RSI) mixed model analyses of variance (ANOVAs) were conducted on RT1 and RT2. The direction of the shift (i.e., GL or LG) was the between-subjects factor, and RSI was the withinsubjects factor. An alpha level less than or equal to .05 was adopted as the criterion for statistical reliability for all analyses. Mean response times are illustrated in Figure 2 by shift direction and RSI.

\section{Response Time to Stimulus 1}

There were no reliable effects involving RT1. Specifically, RT1 did not vary by shift direction $[F(1,32)<1$, $\left.M S_{\mathrm{e}}=173,170\right]$, suggesting that, all else being equal, global and local identifications required equal processing time. Collapsing across RSI, global responses averaged $788 \mathrm{msec}$, and local responses averaged $775 \mathrm{msec}$. The lack of a difference between global and local response times may be surprising, since research on global precedence often finds global responses to be faster than local responses (e.g., Kimchi, 1988; Kimchi \& Palmer, 1985; Navon, 1977; Robertson, 1996; Ward, 1982). However, past research has also shown that global precedence can be mediated by a variety of factors (see Kimchi, 1992, for a review), and as a result, global precedence is not always observed in reaction times to hierarchical stimuli. In addition, level advantages are generally observed when global and local trials are intermixed in a continuous stream. In such cases, global trials are generally faster than local trials when a global trial precedes the judgment. However, it is important to note that in these procedures, local advantages can be observed as well. The methodology in Experiment 1 separated globallocal judgments into isolated pairs, which could have interfered with the ability to observe these effects.

The crucial result in this study is the trend in response times across RSI within GL and LG shifts, with these trends independent of absolute response times. With respect to RT1, no effect of RSI was observed $[F(11,352)=$ $\left.1.3, M S_{\mathrm{e}}=23,925\right]$; this was not surprising, since the RSI manipulation within a trial follows RT1 and the subjects did not know beforehand how long the RSI on a given trial would be. Also, there was no interaction between shift direction and RSI $\left[F(11,352)<1, M S_{\mathrm{e}}=23,925\right]$.

\section{Response Time to Stimulus 2}

Mean RT2 did not vary by shift direction $[F(1,32)<1$, $\left.M S_{\mathrm{e}}=173,170\right]$. This indicates that GL shifts and LG shifts required equal processing time. In both shift conditions, mean RT2 was faster than RT1, averaging $658 \mathrm{msec}$ for GL shifts and $676 \mathrm{msec}$ for LG shifts. RT2 did vary, however, as a function of RSI $[F(11,352)=$ $\left.15.1, M S_{\mathrm{e}}=3,914\right]$. To assess the nature of this relationship, single degree of freedom polynomial tests were conducted. Despite the absence of a shift direction $\times$ 

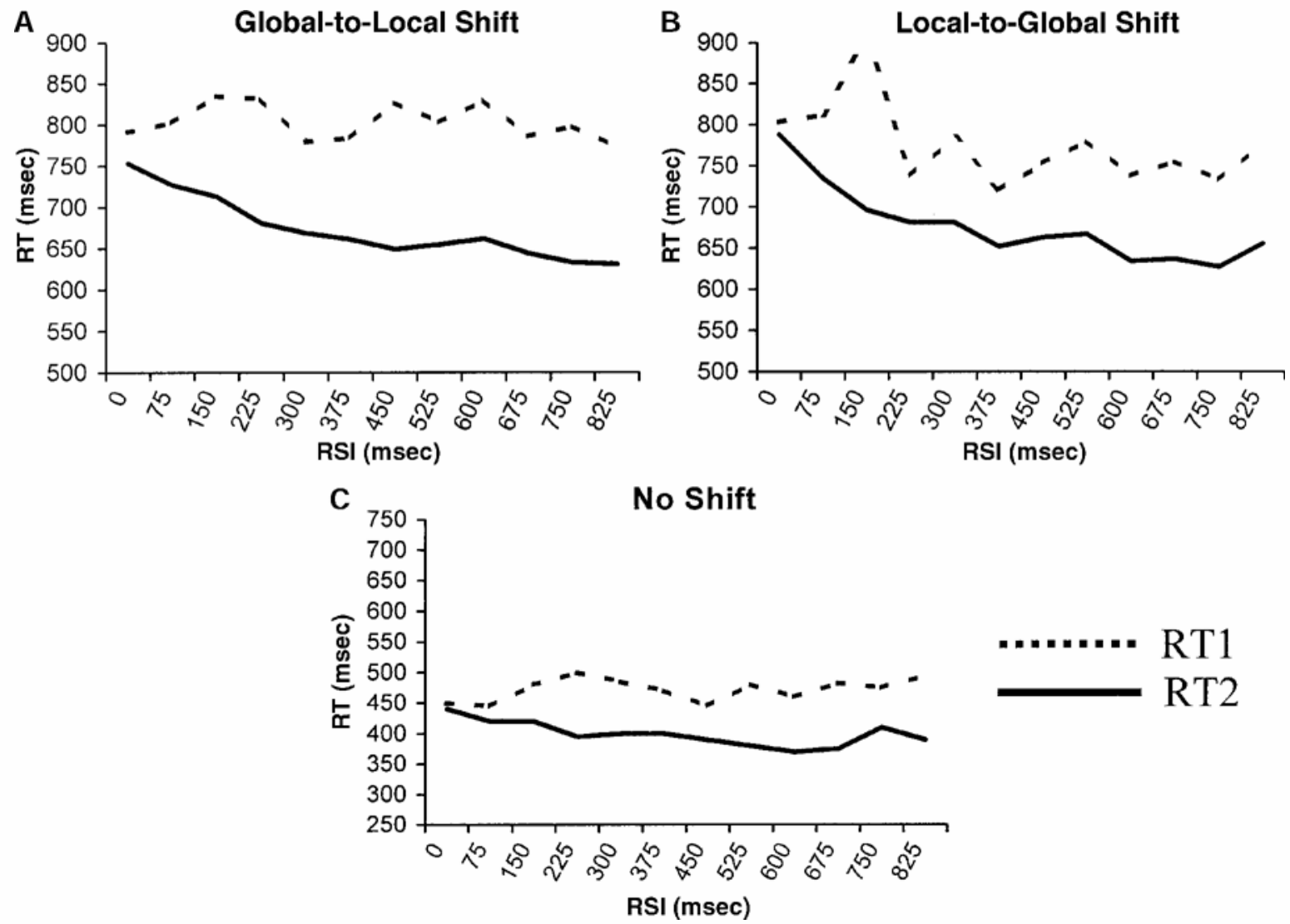

Figure 2. Results of Experiment 1. The graphs illustrate mean response times (RTs) for the first and second stimuli in each trial as a function of the response-to-stimulus interval (RSI). The results for global-to-local shifts are shown in panel A, the results for local-to-global shifts are shown in panel B, and the results for no shifts are shown in panel C. No reliable effects were observed in RT1. When shifts were required, RT2 decreased by RSI through $390 \mathrm{msec}$. When no shifts were required, however, RT2 reached floor at $240 \mathrm{msec}$. This indicates that, when required, shifts of attention occur during the RSI in anticipation of the second figure.

RSI interaction $\left[F(11,352)<1, M S_{\mathrm{e}}=3,914\right]$, the trends for each shift direction were examined separately to further establish that GL shifts and LG shifts require the same amount of processing time.

For GL shifts, reliable negative-slope linear $[F(1,16)=$ $\left.58.9, M S_{\mathrm{e}}=4,045\right]$ and quadratic $\left[F(1,16)=5.6, M S_{\mathrm{e}}=\right.$ $4,954]$ trends were found. Likewise, for LG shifts, reliable negative-slope linear $\left[F(1,16)=46.3, M S_{\mathrm{e}}=6,200\right]$ and quadratic $\left[F(1,16)=12.2, M S_{\mathrm{e}}=6,281\right]$ trends were found. The reliable negative-slope linear trends indicated that RT2 decreased as RSI increased. Reliable quadratic trends indicated that the linear trend did not remain constant across all RSIs. That is, the relationship between RT2 and RSI was curvilinear. In order to demonstrate the presence of an asymptote and estimate the point at which RT2 no longer differed as a function of RSI, a full general linear model consisting of all RSIs was constructed, and RSIs were systematically removed from the model, beginning with the shortest, until a 0 slope linear trend was observed in the data. For both GL shifts and LG shifts, this occurred after removing RSIs less than or equal to $375 \mathrm{msec}$ from the model. To interpolate a more precise estimate of when the RT 2 curve reached asymptote (a point that likely falls between the selected RSIs), a separate assessment of this trend was made, using a spline regression procedure, which is described in detail in the Appendix. This method showed that the RT2 curve reached floor at $390 \mathrm{msec}$.

From this analysis, it appears that bidirectional globallocal shifts of attention require approximately $390 \mathrm{msec}$ to complete. An alternative explanation for the decrease in RT2 with increasing RSI needs to be ruled out before this conclusion can be accepted, however. It is well known that under conditions of temporal uncertainty, RT tends to decrease (up to a point) as the interval between a warning signal and a stimulus increases; this is usually called the foreperiod effect (see Niemi \& Näätänen, 1981, for a review). Therefore, to ensure that the decrease in RT2 was due to a preparatory attention shift across hierarchical stimulus levels and was not merely 
due to the passage of time, another version of Experiment 1 was conducted that did not require switches between global and local levels of the stimuli. Specifically, 12 subjects did not shift attention across levels of the stimuli (i.e., they identified the global shape of both stimuli). Fewer subjects (12) were run in the no-shift condition than in each shift condition (17) because the RT2 data were less variable in the no-shift condition; the standard error of the mean was $5.9 \mathrm{msec}$ in the no-shift condition and $10.7 \mathrm{msec}$ in the shift conditions. As in the shift trials, no reliable effects were observed in RT1 $[F(11,121)=1.6]$. There were differences in RT2 across RSI, however $\left[F(11,121)=16.5, M S_{\mathrm{e}}=416\right]$. These differences were curvilinear in form, as is indicated by a reliable quadratic trend $\left[F(1,11)=33.8, M S_{\mathrm{e}}=1,713\right]$. No differences were observed when RSI was greater than or equal to $225 \mathrm{msec}$. A spline regression procedure indicated that the point at which the RT2 trend reached floor was $240 \mathrm{msec}, 40 \%$ faster than the $390 \mathrm{msec}$ needed when shifts were required. Therefore, although a foreperiod effect may have contributed to the decline of RT2 with increasing RSI in the bidirectional global-local shift conditions, it cannot fully account for the RT2 time courses observed for the shift trials. A time-consuming preparatory shift of attention from one level to the other also must have taken place during the RSI.

To summarize the results of Experiment 1, when shifts of attention were required, volitional global-local shifts of attention took place between stimulus presentations. The reliable quadratic trends in the RT2 data demonstrate that RT2 did not constantly vary with RSI; rather, RT2 reached asymptote after $390 \mathrm{msec}$. Thus, when the eyes remain still, global-local shifts of attention occur between stimulus presentations, and this between-stimulus shift requires approximately $390 \mathrm{msec}$ to complete. With this knowledge, we are now ready to assess whether global-local shifts of attention can occur during saccades.

\section{EXPERIMENT 2}

The critical manipulation in Experiment 2 was the insertion of a saccade between stimulus presentationsprecisely where global-local shifts of attention occurred in Experiment 1 when no saccades were made. According to the attentional suppression hypothesis, because saccadic planning and execution obligatorily engage attention, volitional shifts of attention between global and local dimensions of hierarchical stimuli can no longer occur between stimulus presentations, as they did in Experiment 1, but rather they must occur during the stimulus presentations, when the eyes are still.

In the saccade paradigm introduced in Experiment 2, hierarchical stimuli were not always presented in the same spatial position. When the members of each stimulus pair were presented in spatially distinct locations, the subjects had to move their eyes (either leftward or rightward) to view the second figure. In these cases, the stimuli were separated by either $7.5^{\circ}$ or $40^{\circ}$ of visual angle. Although the first stimulus of every pair was presented in the same location, the subjects did not know where the second stimulus would appear until they responded to the first stimulus. After the first response on some trials, a saccade target appeared in the location where the second stimulus would be presented. The subjects were instructed to move their eyes to this target. The second stimulus was not presented until the termination of the saccade. On other trials, a fixation target appeared in the same location as the first stimulus; this indicated that no saccade was necessary. After a fixed time, the second stimulus then appeared in the same location as the first. Trials that did not require saccades were included in order to deter subjects from adopting a strategy of delaying the global-local attention shift until after the saccade (see Irwin \& Brockmole, 2000, for a further discussion of including no-saccade trials within an eye movement paradigm).

The spatial separation manipulation affected the distance the saccades covered. Because saccade duration depends on saccade distance, $40^{\circ}$ saccades require more time to complete $(110 \mathrm{msec})$ than $7.5^{\circ}$ saccades $(40 \mathrm{msec})$. However, the time required to execute a saccade cannot be measured simply by the saccade's physical duration. Prior to the onset of movement, the saccade must be planned. That is, some measurable saccade latency period, beginning with the onset of the saccade target, exists prior to the start of the saccade. Although saccade latency times can be affected by a variety of variables, in general, saccade latencies fall between 200 and $300 \mathrm{msec}$. Because saccade targets did not appear until after the response to the first stimulus and the second stimulus was not presented until the termination of the saccade, the RSI in Experiment 2 is a simple additive function of saccade latency and saccade duration. The duration of saccadic events, then, constituted the RSI within a trial. Longer saccades afford more time between stimulus presentations than do short saccades, so the longer the saccade, the longer the RSI. In this experiment, the combined saccade latency and duration (RSI) of $7.5^{\circ}$ saccades was approximately $250 \mathrm{msec}$, whereas for $40^{\circ}$ saccades it was approximately $400 \mathrm{msec}$. Based on the results of Experiment 1, in which mean RT2 associated with RSIs of 250 and $375 \mathrm{msec}$ were reliably different from each other $[t(33)=2.7, p=.01]$, this difference in saccade latency and duration should be sufficient to detect a change in RT2, should it exist.

The predictions in Experiment 2 are similar to those in Experiment 1 . There are two possible relationships between saccades and global-local shifts of attention. First, global-local shifts could occur between stimulus presentations (i.e., during saccadic events), as was observed in Experiment 1. Because short $7.5^{\circ}$ saccades are not long enough for the global-local shift to be completed prior to the presentation of the second stimulus, RT2 must absorb some of the time to shift attention. However, 
because long $40^{\circ}$ saccades entail enough time to complete the global-local shift of attention prior to the presentation of the second stimulus, RT2 will not include any time to shift volitional attention. Therefore, if saccades and volitional shifts of attention occur in parallel, RT2 should decrease as the RSI (determined by the duration of saccadic events) increases, as in Experiment 1.

In contrast, the attentional suppression hypothesis predicts that saccades and global-local shifts of attention will occur serially. In this case, increasing the duration of saccadic events (i.e., RSI) will not have a decreasing influence on RT2. Rather, RT2s associated with long saccades may be longer, relative to short saccades, because the extra time added between stimulus presentations by longer saccades does not afford extra time to complete the global-local shift of attention-so the shift may be moved into RT2. Thus, the attentional suppression hypothesis predicts that RT2 should not benefit by increasing the duration of saccadic events (by increasing saccade distance).

In addition to shift conditions, baseline conditions were included in which the subjects did not have to shift attention across levels of the stimuli (i.e., they identified the global shape of both stimuli or the local shape of both stimuli). These no-shift baselines enabled the effects of saccades on response times to be observed when shifts of attention were not required. Predictions for these conditions are straightforward. Because the subjects do not have to shift attention (which requires time), response times should be faster than those for trials in which shifts are necessary. In addition, increasing saccade distance should have a lesser effect on RT2, as compared with shift trials. This is an important result because it ensures that RT2 patterns in the shift trials are the result of attentional suppression, rather than being merely a consequence of longer saccades' causing some additional nonspecific interference, as compared with short saccades, even in the absence of attention shifts. For example, longer saccades may be more difficult to execute or coordinate than shorter saccades, leading to some additional slowing in subsequent processing. Therefore, an interaction between shift condition and saccade distance (i.e., RSI) is expected.

\section{Method}

\section{Subjects}

Sixteen undergraduates at the University of Notre Dame participated after providing informed consent. The subjects were compensated with partial course credit or $\$ 6$ per hour. Four additional subjects were excluded for failure to complete the experiment or for data that were missing owing to the trial trimming procedure (see below). All the subjects were naive with respect to the experimental hypotheses. None of the subjects had participated in Experiment 1.

\section{Stimuli}

The same stimuli as those in Experiment 1 were used.

\section{Apparatus}

The same apparatus as that in Experiment 1 was used, with the following additions and changes. The computer recorded the output from an Applied Science Laboratories Model 210 scleral reflectance eyetracker, which sampled the left eye every $1 \mathrm{msec}$, using an analogto-digital converter. During the experiment, the subject's head was held steady, and a constant distance from the display $(36 \mathrm{~cm})$ was maintained with an anchored bitebar made of dental impression compound. The eyetracker was held in place by an elastic headband. Prior to each trial, the subject completed a calibration routine to calibrate the eyetracker against spatial position. The accuracy of the eyetracker under these conditions is $\pm 0.3^{\circ}$. The subjects made responses to all the stimuli by pressing one of two hand-held microswitches interfaced with the computer via a digital input board.

\section{Design}

Within subjects, a pair of stimuli were presented on each trial. For each stimulus, the subjects identified the global form or local elements by indicating square or rectangle. There were four instruction conditions: identify global for both stimuli, identify local for both, identify global for first and local for second, and identify local for first and global for second. These four types of instructions were blocked. Within each block, there were three eye movement distances presented in random order. Saccade distances were $0^{\circ}$ (stimuli were presented in same spatial location), $7.5^{\circ}$, or $40^{\circ}$ of visual angle. On two thirds of the trials in each block, no saccade was required. On one sixth of the trials, a saccade of $7.5^{\circ}$ was required between the presentation of the two stimuli, and on one sixth of the trials, a $40^{\circ}$ saccade was required. The no-saccade trials were included in order to deter the subjects from deferring the shift of attention until after the saccade (see Irwin \& Brockmole, 2000). Half of the subjects generated saccades to the right, and half of the subjects generated saccades to the left. This factor was not randomly assigned (i.e., the rightward-saccade condition was run several months before the leftward-saccade condition). Thus, saccade direction was a between-subjects factor.

The four figures were combined into all 16 possible pairs. Shift direction was blocked (four blocks: GG, LL, GL, LG). Within each block a condition factor of six was used (four for $0^{\circ}$ saccade trials, one for $7.5^{\circ}$ saccade trials, one for $40^{\circ}$ saccade trials); this maintained the 1:1:4 ratio between $40^{\circ}$ saccade, $7.5^{\circ}$ saccade, and nosaccade trials. Thus, each block contained 96 trials. All the subjects completed all four blocks, yielding a total of 384 trials per subject.

Each subject participated in three sessions conducted on different days. The first session familiarized the subjects with the task; no data from this session were entered into the analyses. During this session, the subjects completed 20 trials at each saccade distance for each instruction type. In the second and third sessions, each subject completed two blocks of trials in yoked instruction conditions. Specifically, in one session, the subjects would receive the GG and GL blocks, and in the other session, they would receive the LL and LG blocks. The order of blocks within a session and the order of sessions were counterbalanced across subjects. During the second and third sessions, the subjects completed 96 practice trials at a saccade distance of $0^{\circ}$ and then 10 practice trials that included saccade distances of $7.5^{\circ}$ and $40^{\circ}$ prior to each block of 96 experimental trials. The purpose of this practice was to ensure that the subjects were comfortable with the particular instruction condition.

\section{Procedure}

To illustrate the general procedure, Figure 3 schematically depicts the events on saccade and no-saccade trials within the rightwardsaccade condition. For leftward saccades, the analogous procedure was used, with the locations of the stimuli reversed. On all trials, the subjects began a trial by completing a calibration routine, during which a dark blue "+" sign (subtending $0.2^{\circ}$ horizontally and $0.4^{\circ}$ vertically) stepped across the screen in five locations, each separated by $12^{\circ}$ of visual angle. Calibration direction was consistent with saccade direction. Each of the five locations was fixated for $1,500 \mathrm{msec}$. The subject's eye position was monitored, and the output was used to calibrate the eyetracker with spatial position. 


\section{Saccade Trials}

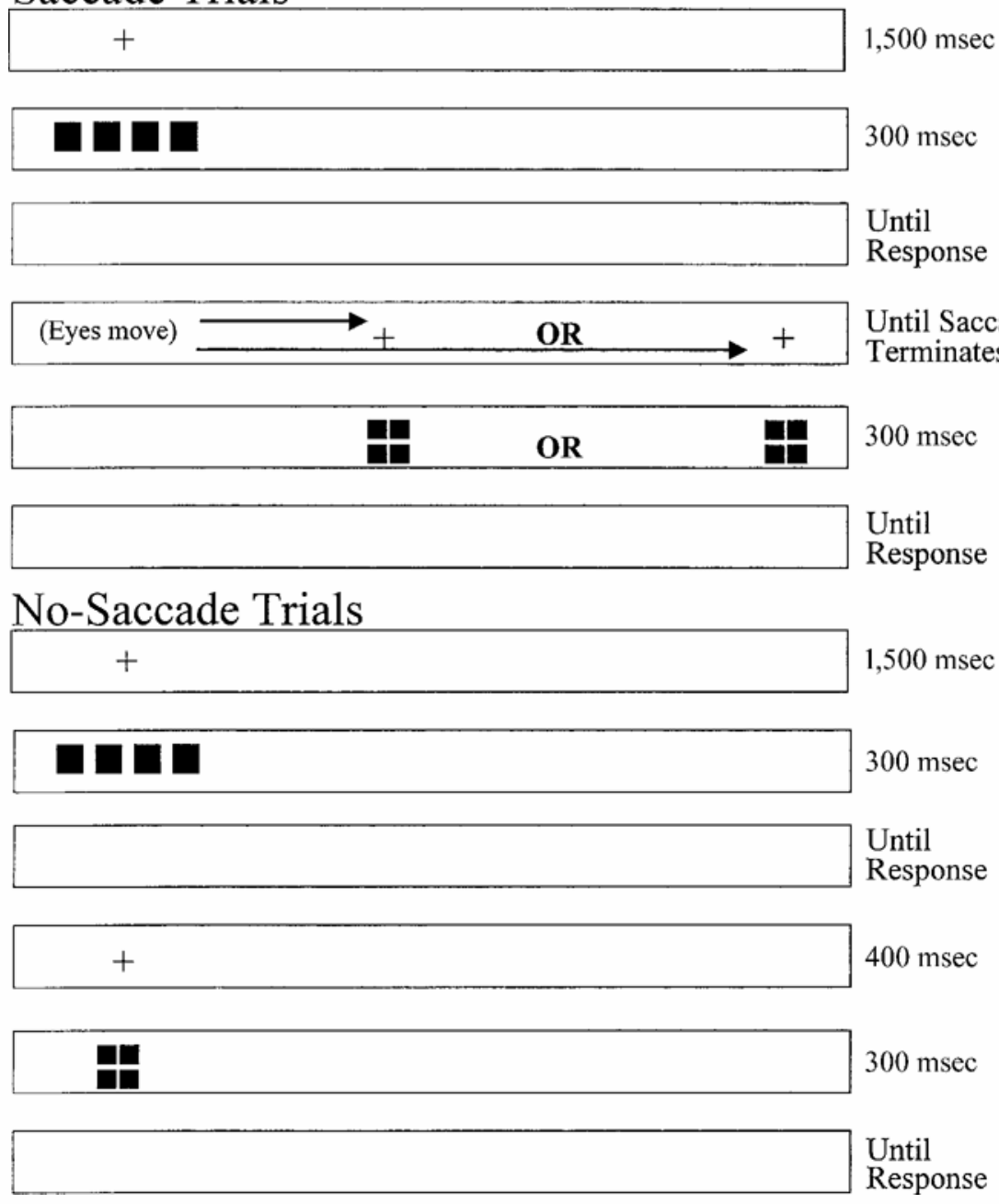

Figure 3. Schematic illustration of the procedure in Experiment 2.

After calibration, a fixation cross appeared $20^{\circ}$ left of center. The subject fixated this cross for $1,500 \mathrm{msec}$, whereupon the first stimulus was presented for $300 \mathrm{msec}$. The subjects made a response to this stimulus, using hand-held microswitches (the switch in the subject's dominant hand always corresponded to square, and the other to rectangle). Then, a saccade target appeared $20^{\circ}$ left of center (i.e., at the same location as the first stimulus, indicating that no saccade was necessary), $12.5^{\circ}$ left of center (indicating that a $7.5^{\circ}$ saccade was necessary), or $20^{\circ}$ right of center (indicating that a $40^{\circ}$ saccade was necessary). For leftward saccades, the initial stimulus was presented $20^{\circ}$ right of center, and saccade targets were presented in the same location, $12.5^{\circ}$ right of center, or $20^{\circ}$ left of center. For saccade trials, the target was presented until the termination of the saccade. In all cases, the onset of a saccade was defined as a change in eye position in the same direction that exceeded $0.05 \mathrm{deg} / \mathrm{msec}$ for 3 consecutive milliseconds. The saccade was considered completed when this criterion was no longer met. For no-saccade trials, the target was presented for $400 \mathrm{msec}$, an a priori estimate of saccade latency and duration in eye movement trials. Finally, the second stimulus was presented for $300 \mathrm{msec}$ at the location of the given saccade target, and responses were collected.
The subjects were told to respond as quickly but as accurately as possible to both stimuli.

\section{Results and Discussion}

Analyses focused on trials in which both stimuli were incongruent. Trials were also excluded for inappropriate eye movement or response behavior. Specifically, a trial was considered unacceptable if (1) either response was incorrect or if a response was not made $(6 \%),(2)$ the first response was not made within $1,500 \mathrm{msec}(1 \%)$, (3) no saccade was made on eye movement trials (1\%), or (4) if saccades did not land within $3.5^{\circ}$ of the target fixation cross $(3 \%)$. A combination of the above occurred on $2 \%$ of the trials. In sum, $9 \%$ of the trials were excluded from the analyses by this trimming process.

The structure of the Results and Discussion section is as follows. First, we present the no-saccade data to demonstrate that the need to execute eye movements on 


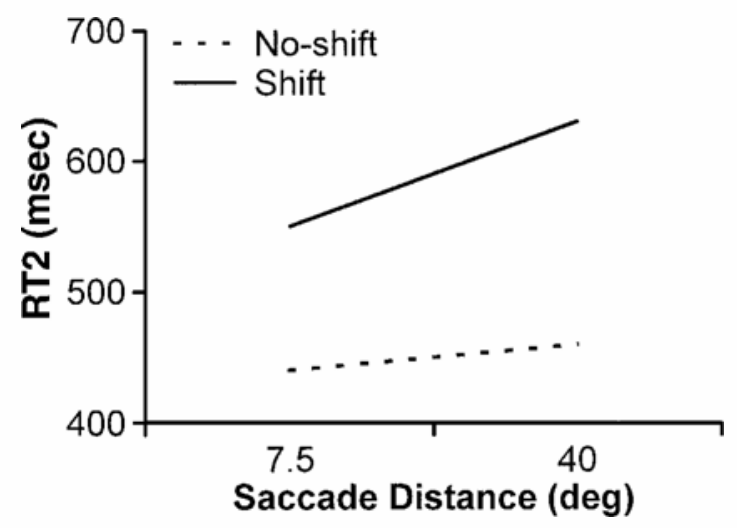

Figure 4. Response time to second stimulus (RT2) patterns in Experiment 2, where saccades intervened between stimulus presentations. When shifts of attention were required, RT 2 increased as saccade distance (and thus the interval between response and stimulus [RSI]) increased. This effect interacted with the much smaller growth when no shifts of attention were necessary. This indicates that shifts of attention were suppressed during the saccadic events within the RSI period over and above any general interference caused by saccades.

the saccade trials does not alter the characteristics and the time course of the attention shift observed in Experiment 1 . Second, we demonstrate that the critical effects are independent of saccade direction, enabling us to collapse across this variable in the critical analyses. These analyses enable us to focus on the question of interest: whether subjects can make use of the additional time afforded by the longer eye movement to shift attention. To address this question, the critical data of interest concern the effect of saccade distance on RT2 (plotted in Figure 4). However, RT2 can be considered only in light of the other components (saccade latency, saccade duration, and RT1). For example, saccade latency and duration determine the trial RSI, which is crucial to interpreting RT2 data patterns (i.e., does RT2 decrease as RSI increases?). Accordingly, we present the results broken down by each of these trial components.

\section{No-Saccade Trials}

Trials that did not involve saccades were analyzed separately from saccade trials because no-saccade and saccade trials place discrepant task demands on the subject. Whenever we are engaged in some task (not necessarily visual) and moving our eyes at the same time, a dual-task situation arises that may produce interference (Pashler, Carrier, \& Hoffman, 1993). On no-saccade trials, however, this interference is absent. Therefore, direct comparisons between no-saccade and saccade trials are inappropriate.

The no-saccade trials are valuable in and of themselves, however, because they constitute a partial replication of Experiment 1 (during which saccades were never made) under conditions in which saccades were sometimes made. That is, the no-saccade trials in Experiment 2 are similar to those in Experiment 1 in that no saccades were generated, but different in that they were housed within a block of trials in which saccades were sometimes required. The no-saccade trials in Experiment 2 can therefore be analyzed to address whether the general RT patterns observed in Experiment 1 were also observed in Experiment 2, with the goal of ensuring that the potentially different task demands in Experiment 2 did not alter the characteristics and the time course of the attention shift observed in Experiment 1. The mean response times to the first and second stimuli for no-saccade trials in Experiment 2 are reported in Table 1. Recall that the RSI associated with these no-saccade trials was always $400 \mathrm{msec}$.

The no-saccade trials of Experiment 2 replicated the corresponding results of Experiment 1 in two important respects. First, RT2 was faster than RT1. Collapsing across saccade direction (no-saccade trials were intermixed with saccade trials that were blocked by direction) and shift direction, the RT1-RT2 difference was $90 \mathrm{msec}$. In Experiment 1, this difference was $96 \mathrm{msec}$ when the RSI was $375 \mathrm{msec}$. Thus, although the entire RSI $\times$ RT2 function was not mapped out in Experiment 2, the consistency between the experiments on this point suggests that the more difficult Experiment 2 (more difficult because saccades were added to the design) did not alter this function within the temporal window of interest.

Second, in both experiments, not only was RT2 slowed when shifts of attention (GL, LG trials) were required, relative to cases where no shifts (GG, LL trials) were required (by $168 \mathrm{msec}$ in Experiment 2 and by $243 \mathrm{msec}$

Table 1

No-Saccade Trial Results, Experiment 2: Mean Response Times to Stimulus 1 (RT1) and Stimulus 2 (RT2, in Milliseconds) by Saccade Direction Condition (No-Saccade and Saccade Trials Were Intermixed) and Shift Condition

\begin{tabular}{|c|c|c|c|c|c|c|c|c|}
\hline \multirow[b]{2}{*}{ Component } & \multicolumn{4}{|c|}{ Within Rightward-Saccade Blocks } & \multicolumn{4}{|c|}{ Within Leftward-Saccade Blocks } \\
\hline & GG & LL & GL & LG & GG & LL & GL & $\mathrm{LG}$ \\
\hline RT1 & 480 & 480 & 682 & 643 & 422 & 468 & 600 & 596 \\
\hline RT2 & 408 & 413 & 600 & 518 & 375 & 394 & 538 & 506 \\
\hline
\end{tabular}

Note-RSI was 400 msec. GG, global-global; LL, local-local; GL, global-local; LG, local-global. 
in Experiment 1 when RSI $=375 \mathrm{msec}$ ), but so too was RT1 (by $143 \mathrm{msec}$ in Experiment 2 and by $320 \mathrm{msec}$ in Experiment 1 when RSI $=375 \mathrm{msec}$ ). At first glance, it may seem surprising that RT1 is also slowed when shifts are required, but there may be two factors that contribute to this RT1 elevation. First, shifting attention may not be entirely restricted to the RSI but may begin before the first stimulus is completely processed. Second, on noshift (GG, LL) trials, subjects make the same judgment throughout the experiment, but on shift (GL, LG) trials, subjects have to remember to keep shifting between the levels of the hierarchical stimulus throughout the experiment. This additional memory load and alternation of task set may well slow response times. Note that this slowing is not relevant to the question of whether attention is suppressed during saccades, since it occurs before the response to the first stimulus and it occurs even when the eyes are still.

\section{Rightward Versus Leftward Saccades}

A between-subjects analysis was performed to determine whether any reliable differences existed between rightward and leftward saccades among the variables of interest. Mean RT1s, saccade latency, saccade duration, and mean RT2s are summarized in Table 2, broken down by saccade direction, saccade distance, and shift condition.

Only a reliable main effect of saccade latency was observed $\left[F(1,14)=5.06, M S_{\mathrm{e}}=18,933\right]$, with rightward saccades having longer latencies. This effect did interact with saccade distance $\left[F(1,14)=8.15, M S_{\mathrm{e}}=5,374\right]$, but not with instruction condition $[F(3,42)<1]$. Specifically, latencies for saccades generated to the right were longer than latencies for saccades generated to the left. For short saccades, mean latency difference was $18 \mathrm{msec}$ ( $M=216$ and $198 \mathrm{msec}$ for rightward and leftward saccades, respectively); for long saccades, the mean latency difference was $92 \mathrm{msec}$ ( $M=341$ and $249 \mathrm{msec}$ for rightward and leftward saccades, respectively). Accordingly, mean RSI differed for rightward and leftward saccades (rightward, $258 \mathrm{msec}$ for short and $450 \mathrm{msec}$ for long saccades, respectively; leftward, $239 \mathrm{msec}$ for short and $355 \mathrm{msec}$ for long saccades, respectively). However, based upon the results of Experiment 1, in both cases the difference between RSIs associated with short and long saccades was sufficient to produce reliable differences in RT2 [in Experiment 1, RSIs of 225 and $450 \mathrm{msec}$ reliably differed, $t(33)=2.3, p=.03$, as did RSIs of 225 and $375 \mathrm{msec}, t(33)=2.7, p=.01 \mathrm{]}$. Because of this, the same qualitative pattern in RT2 would be observed in both leftward and rightward saccades if attention is or is not suppressed, despite the differences in saccade latency. ${ }^{3}$ Furthermore, because no reliable differences were observed in the RT1 $[F(1,14)<1]$, saccade duration $[F(1,14)=1.36]$, or RTs $[F(1,14)=1.6]$, the remaining analyses collapse across saccade direction (see Table 3 ).

\section{Analysis of Trial Components}

Each trial can be broken down into four temporally distinct components: RT1, saccade latency, saccade duration, and RT2. However, each of these components can influence subsequent components. Thus, effects observed within each trial component are discussed separately. Each component was analyzed using a 4 (shift condition) $\times 2$ (saccade distance) repeated measures ANOVA.

\section{Response Time to Stimulus 1}

A main effect of shift condition was found $[F(3,45)=$ $\left.16.8, M S_{\mathrm{e}}=15,909\right]$. No main effect of saccade distance was found, however $[F(1,15)<1]$, and there was no interaction $[F(3,45)<1]$. Planned comparisons showed trials requiring a global-local attention shift (GL and LG) were reliably slower $(M=632)$ than trials that did not require this shift [GG, LL; $M=477 \mathrm{msec} ; F(1,15)=$ $\left.35.1, M S_{\mathrm{e}}=175,017\right]$, yielding a difference of $155 \mathrm{msec}$. This difference is very similar to that observed on nosaccade trials, discussed earlier. Within each shift type, a marginal difference in RT1 between global no-shift trials $(M=454 \mathrm{msec})$ and local no-shift trials $[M=$ $\left.500 \mathrm{msec} ; F(1,15)=3.77, M S_{\mathrm{e}}=35,608, p=.07\right]$ was

Table 2

Saccade Trial Results, Experiment 2: Mean Response Time to Stimulus 1 (RT1), Saccade Latency, Saccade Duration, and Response Time to Stimulus 2 (RT2; in Milliseconds) by Saccade Direction, Saccade Distance, and Shift Condition

\begin{tabular}{|c|c|c|c|c|c|c|c|c|}
\hline \multirow[b]{2}{*}{ Component } & \multicolumn{4}{|c|}{$7.5^{\circ}$} & \multicolumn{4}{|c|}{$40^{\circ}$} \\
\hline & GG & LL & GL & LG & GG & LL & GL & LG \\
\hline \multicolumn{9}{|c|}{ Rightward Saccades } \\
\hline RT1 & 507 & 491 & 629 & 659 & 470 & 508 & 635 & 689 \\
\hline Saccade Latency & 218 & 208 & 217 & 222 & 306 & 328 & 376 & 354 \\
\hline Saccade Duration & 43 & 40 & 43 & 42 & 108 & 108 & 111 & 110 \\
\hline RT2 & 480 & 463 & 635 & 529 & 486 & 493 & 664 & 637 \\
\hline \multicolumn{9}{|c|}{ Leftward Saccades } \\
\hline RT1 & 430 & 504 & 630 & 587 & 408 & 495 & 644 & 581 \\
\hline Saccade Latency & 184 & 199 & 200 & 210 & 237 & 258 & 244 & 258 \\
\hline Saccade Duration & 42 & 40 & 40 & 39 & 103 & 105 & 108 & 107 \\
\hline RT2 & 390 & 424 & 536 & 523 & 430 & 444 & 595 & 609 \\
\hline
\end{tabular}

Note-GG, global-global; LL, local-local; GL, global-local; LG, local-global. 
Table 3

Saccade Trial Results, Experiment 2, Collapsing Across Saccade Direction

\begin{tabular}{|c|c|c|c|c|c|c|c|c|}
\hline \multirow[b]{2}{*}{ Component } & \multicolumn{4}{|c|}{$7.5^{\circ}$} & \multicolumn{4}{|c|}{$40^{\circ}$} \\
\hline & GG & LL & GL & $\mathrm{LG}$ & GG & LL & GL & $\mathrm{LG}$ \\
\hline RT1 & 469 & 498 & 629 & 623 & 439 & 502 & 639 & 635 \\
\hline Saccade Latency & 201 & 204 & 209 & 216 & 271 & 293 & 310 & 306 \\
\hline Saccade Duration & 42 & 40 & 41 & 41 & 106 & 107 & 109 & 108 \\
\hline RT2 & 435 & 444 & 586 & 526 & 458 & 468 & 630 & 623 \\
\hline
\end{tabular}

Note-GG, global-global; LL, local-local; GL, global-local; LG, local-global; RT1, response time to Stimulus 1; RT2, response time to Stimulus 2. Results are given in milliseconds.

observed, which is consistent with global precedence. However, GL shifts $(M=634 \mathrm{msec})$ did not reliably differ from LG shifts $[M=629 \mathrm{msec} ; F(1,7)<1]$. In summary, RT1 was primarily influenced by the need to shift attention across stimulus levels, but some evidence was obtained for a global precedence effect when no shifts were required.

\section{Response to Stimulus Interval}

The RSI is the sum of saccade latency and saccade duration; each is considered individually below. On average, $7.5^{\circ}$ saccades produced an RSI of $248 \mathrm{msec}$, and $40^{\circ}$ saccades produced an RSI of $403 \mathrm{msec}$. In general, then, $40^{\circ}$ saccades provided an additional $155 \mathrm{msec}$ between stimulus presentations than did $7.5^{\circ}$ saccades. RSIs associated with the shorter saccades were less than the Experiment 1 estimate of $390 \mathrm{msec}$ to complete the globallocal shift, whereas RSIs associated with longer saccades exceeded it. Thus, the RSIs produced by short versus long saccades should be appropriate for revealing whether shifts of attention across the levels of a hierarchical stimulus can take place during saccades.

Saccade latency. No main effect of shift condition was found $[F(3,45)=1.8 ; M=236,248,259$, and $261 \mathrm{msec}$ for GG, LL, GL, and LG trials, respectively]. However, a main effect of saccade distance was found $\left[F(1,15)=31.0, M S_{\mathrm{e}}=2,276\right]$, where mean saccade latency prior to $7.5^{\circ}$ saccades $(207 \mathrm{msec})$ was shorter than that for $40^{\circ}$ saccades $(295 \mathrm{msec})$. The mean difference was $88 \mathrm{msec}$. The saccade distance effect did not interact with shift condition $[F(3,45)<1]$.

Saccade duration. No main effect of shift condition was found $[F(3,45)<1]$, indicating that saccade duration did not vary by shift condition $(M=74,73,75$, and $75 \mathrm{msec}$ for GG, LL, GL, and LG trials, respectively). As was expected, a main effect of saccade distance was found $\left[F(1,15)=943.5, M S_{\mathrm{e}}=149\right]$, where $7.5^{\circ}$ saccades $(41 \mathrm{msec})$ took less time to complete than $40^{\circ}$ saccades (108 msec). The mean difference was $67 \mathrm{msec}$. The saccade distance effect did not interact with shift condition $[F(3,45)=1.4]$.

\section{Response Time to Stimulus 2}

The effect of shifting attention between stimulus levels. A main effect of shift condition was found $\left[F(3,45)=39.3, M S_{\mathrm{e}}=5,485\right]$. Trials requiring a global- local attention shift (GL and LG) were reliably slower $(M=591 \mathrm{msec})$ than trials that did not require this shift [GG, LL; $M=451 \mathrm{msec} ; F(1,15)=97.9, M S_{\mathrm{e}}=51,236$ ]. Global no-shift trials $(M=446 \mathrm{msec})$ did not reliably differ from local no-shift trials $[M=456 \mathrm{msec} ; F(1,15)<$ 1]; however, there was a marginal difference between GL shifts $(M=608 \mathrm{msec})$ and LG shifts $[M=575 \mathrm{msec}$; $\left.F(1,15)=2.92, M S_{\mathrm{e}}=23,923, p=.11\right]$. This potential difference would be consistent with a global precedence effect. In summary, RT2 for no-shift trials was faster than that for shift trials by a mean of $140 \mathrm{msec}$.

The effect of saccades. The primary concern of Experiment 2 is the effect of saccade distance (i.e., RSI) on RT2. Figure 4 illustrates the RT2 data with respect to the RSIs generated by short and long saccades. A reliable main effect of saccade distance was found $[F(1,15)=$ $\left.34.8, M S_{\mathrm{e}}=2,042\right]$. In general, mean RT2 for $40^{\circ}$ saccades $(M=545 \mathrm{msec})$ were $47 \mathrm{msec}$ longer than that for $7.5^{\circ}$ saccades $(M=498 \mathrm{msec})$. Note that this pattern is directly opposite to the one that would occur if globallocal shifts of attention could be executed in parallel with saccades. There was a reliable interaction between shift condition and saccade distance $\left[F(3,45)=2.96, M S_{\mathrm{e}}=\right.$ $3,174]$. Specifically, when no shifts were required, RT2 for $40^{\circ}$ saccades was $24 \mathrm{msec}$ longer than that for $7.5^{\circ}$ saccades. This growth in RT2 was reliably greater than zero, based on a $95 \%$ confidence interval $(7-41 \mathrm{msec})$. This effect is important for two reasons. First, it demonstrates sufficient power to detect a $24-\mathrm{msec}$ effect. Second, it indicates that longer saccades may have generated more interference than did shorter saccades. Most important, however, for shift trials, RT2 for $40^{\circ}$ saccades was nearly three times as large $(70 \mathrm{msec})$ as RT2 for $7.5^{\circ}$ saccades. Thus, there was an additional and significant cost in RT2 on shift trials over and above any cost associated with executing a longer saccade. This indicates that the extra time provided by the long saccades was not used to shift global-local attention.

The results of Experiment 2 are consistent with the predictions of the attentional suppression hypothesis. Short $7.5^{\circ}$ saccades generated an RSI well below the time necessary to complete bidirectional global-local shifts of attention, whereas RSIs associated with long $40^{\circ}$ saccades exceeded this time frame. However, RT2 did not decrease as saccade distance (and thus RSI) increased, as would be expected if global-local shifts of 
attention occurred during saccadic events. This demonstrates that the additional time offered by the $40^{\circ}$ saccades was not used to execute the global-local shift of attention. In fact, RT2 increased, indicating that the shift of attention was, at least in part, delayed until after the completion of the saccade. Saccades and global-local shifts of attention do not occur in parallel. ${ }^{4}$

\section{GENERAL DISCUSSION}

Recent research suggests that saccades suppress some, but not all, cognitive processes. The purpose of the present experiments was to address an attentional suppression hypothesis in order to account for these findings. This hypothesis states that when attention is engaged by saccadic planning and execution, it is unable to direct attention-demanding higher order cognitive processes. Using a global-local judgment task, the effect of saccades on attention was examined. When attention is shifted from global to local or from local to global levels of hierarchical figures, the allocation of attention must be switched across dimensions. This shift did not take place during saccadic planning and execution, a result supportive of the attentional suppression hypothesis.

The hypothesis that saccades interfere with the allocation of attention to higher order cognitive processes accounts for the fact that cognitive functions inhibited by saccades, in addition to global-local shifts of attention, are slow and effortful (e.g., enumeration, Matin et al., 1993; mental rotation, Irwin \& Brockmole, 2000, and Irwin \& Carlson-Radvansky, 1996; "filling in" of degraded stimuli, Sanders \& Houtmans, 1985, and Sanders $\&$ Rath, 1991), whereas automatic processes seem to carry on normally during saccades (lexical processing, Irwin, 1998; priming, Irwin et al., 1995). However, it is difficult to conceive of each of these suppressed tasks as involving attention in the same way. So, what is meant by attention, and what mechanisms underlie saccadic inhibition of attended processes? We address these in order.

First, what is meant by attention? In the present context, Robertson and her colleagues (e.g., Robertson, 1996; Robertson, Egly, et al., 1993; Robertson \& Lamb, 1991) have extensively studied the nature of attention in the global-local paradigm. Their research suggests that two types of attention shifts occur in this task. The first is categorical, and the second is regional. In order to identify a stimulus, attention must be categorically assigned to either its global or its local level. When the dimension of interest changes, attention must be shifted to the opponent level. This allocation of attention is independent of the region of space the figure occupies and is determined by the properties of the attended stimulus (Robertson, Egly, et al., 1993). Robertson, Egly, et al. have proposed that categorical shifts of attention may be accomplished by focusing attention on different spatial frequency channels, for example. In some ways, categorical attention seems similar to the notion of object-based at- tention (e.g., Duncan, 1984). Regional attention, on the other hand, is much like a spotlight that expands and contracts to encompass the space around an object. Switching interest from small to large objects (or to parts within an object) requires an adjustment of this window. The research reported in the present paper did not attempt to disentangle these two forms of attention. More direct empirical investigations of what forms of attention are suppressed during saccades constitute an important avenue for future research. For example, Robertson, Egly, et al. dissociated these forms of attention by providing global or local cues prior to the target, manipulating the stimulus onset asynchrony between cue and target, and biasing global or local responding within blocks. A transsaccadic version of this paradigm may be able to assess whether categorical, regional, or both categorical and regional attention is suppressed across saccades.

Second, what mechanisms underlie saccadic inhibition of attended processes? Irwin and his colleagues (Irwin, 1998; Irwin \& Brockmole, 2000; Irwin \& CarlsonRadvansky, 1996; Irwin et al., 1995) have suggested that it may be useful to view the problem of cognitive suppression as one of dual-task interference. Although saccades seem effortless, they require attention to program and execute, and as such, whenever we are moving our eyes, we are in a dual-task situation. Viewed from this perspective, an account must be given as to why some dual-task situations produce suppression, whereas others do not. The attentional suppression hypothesis provides such an account.

When a saccade is planned, attention is directed to the to-be-fixated location. This allocation of attention to saccade targets is obligatory and involuntary. If we view attention as a limited-capacity resource (Kahneman, 1973), this generates a type of dual-task interference that results in less available attention to direct other processes. Because of the importance of saccades in viewing the world, attention related to the guidance of eye movements is given priority over uses of attention related to other kinds of cognitive processes. Thus, cognitive suppression occurs only in situations in which we attempt to engage in attention-demanding processes concurrently with saccades, whereas tasks that do not require attention carry on during saccades.

Although an attention-based account of cognitive suppression provides an explanation of the current literature, another hypothesis concerning the source of the phenomenon that suggests attention is not the common link among suppressed processes is possible. For example, it may be the functional characteristics of the brain that underlie cognitive suppression. In this view, dualtask interference, or suppression, results when two behaviors rely on similar or related brain structures (see, e.g., Kinsbourne, 1980). Thus, cognitive suppression arises when eye movements and a particular cognitive process share neural substrates. Indeed, there is evidence that mental rotation (e.g., Farah, 1988; Finke, 1980) and attention associated with global-local tasks (Rafal \& 
Robertson, 1985; Robertson, Egly, et al., 1993) rely on similar brain structures as those that generate saccades. Evidence supporting a pure neurological dual-task hypothesis is far from complete, however, since the relationship between brain areas controlling saccades and those involved in memory search and enumeration (other suppressed tasks) is much less clear.

Another difficulty with the neurological dual-task hypothesis is raised by the data presented in this report. Global-local discriminations exhibit hemispheric asymmetries in that local judgments are processed in the left hemisphere and global judgments are processed in the right hemisphere (Delis, Robertson, \& Efron, 1986; Lamb, Robertson, \& Knight, 1990; Martin, 1979; Robertson, Lamb, \& Zaidel, 1993; Van Kleek, 1989). Given this difference, one could expect different forms of suppression to have emerged, depending on the direction of the saccade. For example, if switching to a local process encumbers the left hemisphere, the suppression might be observed for GL shifts when the eyes move to the right, but not when they move to the left (saccade direction is controlled by the contralateral hemisphere). Similarly, if the right hemisphere is encumbered by switching to global processing, LG shifts should be suppressed during leftward saccades, but not during rightward saccades. No such interactions were observed in the data, however, suggesting that hemispheric asymmetries may not underlie the suppression of global-local shifts of attention solely.

The attentional suppression hypothesis and a neurologically based dual-task hypothesis may not necessarily be mutually exclusive, however. Rather, they may be viewed as different levels of explanation. Brain regions responsible for a particular form of attention are likely involved in many manifestations of attention used in various cognitive tasks. Thus, it is possible that task demands at the neural level cause the suppression of attention during saccades. That is, dual-task interference may reflect the mechanism that produces cognitive suppression, which results in the behaviorally observed inhibition of higher order cognitive functions. In order to address these issues, further research on cognitive suppression must aim at falsifying either the attentional suppression hypothesis, by finding attended tasks that are not suppressed during saccades, or a neurologically based dualtask hypothesis, by finding suppression of an attentional task that clearly does not rely on brain structures that control saccades.

\section{REFERENCES}

Breitmeyer, B. G., Kropfl, W., \& Julesz, B. (1982). The existence and role of retinotopic and spatiotopic forms of visual persistence. Acta Psychologica, 52, 175-196.

BRIDGEMAN, B., \& MAYER, M. (1983). Failure to integrate visual information from successive fixations. Bulletin of the Psychonomic Society, 21, 285-286.

Carlson-Radvansky, L. A. (1999). Memory for relational information across eye movements. Perception \& Psychophysics, 61, 919934.
Carlson-Radvansky, L. A., \& Irwin, D. E. (1995). Memory for structural information across eye movements. Journal of Experimental Psychology: Learning, Memory, \& Cognition, 21, 1441-1458.

Currie, C. B., McConkie, G. W., Carlson-Radvansky, L. A. \& IRWIN, D. E. (2000). The role of the saccade target object in the perception of a visually stable world. Perception \& Psychophysics, 62, 673-683.

Delis, D. C., Robertson, L. C., \& Efron, R. (1986). Hemispheric specialization of memory for visual hierarchical stimuli. Neuropsychologia, 24, 205-214.

Deubel, H., \& Schneider, W. X. (1996). Saccade target selection and object recognition: Evidence for a common attentional mechanism. Vision Research, 36, 1993-1997.

DunCAN, J. (1984). Selective attention and the organization of visual information. Journal of Experimental Psychology: General, 113, 501517.

FARAH, M. (1988). Is visual imagery really visual? Overlooked evidence from neuropsychology. Psychological Review, 95, 307-317.

FINKE, R. A. (1980). Levels of equivalence in imagery and perception. Psychological Review, 87, 113-132.

HENDERSON, J. M. (1997). Transsaccadic memory and integration during real-world object perception. Psychological Science, 8, 51-55.

Henderson, J. M., \& Hollingworth, A. (1999). The role of fixation position in detecting scene changes across saccades. Psychological Science, 10, 438-443.

Hoffman, J. E., \& Subramaniam, B. (1995). The role of visual attention in saccadic eye movements. Perception \& Psychophysics, 57, 787-795.

Hollingworth, A., \& Henderson, J. M. (2002). Accurate visual memory for previously attended objects in natural scenes. Journal of Experimental Psychology: Human Perception \& Performance, 28, 113-136.

IRWIN, D. E. (1991). Information integration across saccadic eye movements. Cognitive Psychology, 23, 420-456.

IRWIN, D. E. (1992). Memory for position and identity across eye movements. Journal of Experimental Psychology: Learning, Memory, \& Cognition, 18, 307-317.

IRwIN, D. E. (1996). Integrating information across saccadic eye movements. Current Directions in Psychological Science, 5, 94-100.

IrwIN, D. E. (1998). Lexical processing during saccadic eye movements. Cognitive Psychology, 36, 1-27.

IRwin, D. E., \& BRocKmole,J. R. (2000). Mental rotation is suppressed during saccadic eye movements. Psychonomic Bulletin \& Review, 7 , 654-661.

IRwIN, D. E., BRown, J. S., \& Sun, J. S. (1988). Visual masking and visual integration across saccadic eye movements. Journal of Experimental Psychology: General, 117, 276-287.

Irwin, D. E., \& CARlson-Radvansky, L. A. (1996). Cognitive suppression during saccadic eye movements. Psychological Science, 7, 83-88.

Irwin, D. E., Carloson-Radvansky, L. A., \& Andrews, R. (1995). Information processing during saccadic eye movements. Acta Psychologica, 90, 261-273.

IRWIN, D. E., \& Gordon, R. D. (1998). Eye movements, attention, and trans-saccadic memory. Visual Cognition, 5, 127-155.

IRWIN, D. E., Yantis, S., \& Jonides, J. (1983). Evidence against visual integration across saccadic eye movements. Perception \& Psychophysics, 34, 49-57.

Kahneman, D. (1973). Attention and effort. Englewood Cliffs, NJ: Prentice-Hall.

KIмchi, R. (1988). Selective attention to global and local levels in comparison of hierarchical patterns. Perception \& Psychophysics, 43, 189-198.

KIмcHI, R. (1992). Primacy of wholistic processing and global/local paradigm: A critical review. Psychological Bulletin, 112, 24-38.

Kimchi, R, \& Palmer, S. E. (1985). Separability and integrality of global and local levels of hierarchical patterns. Journal of Experimental Psychology: Human Perception \& Performance, 11, 673-688.

Kinchla, R. A., Solis-Marcias, V., \& Hoffman, J. (1983). Attending to different levels of structure in a visual image. Perception \& Psychophysics, 33, 1-10. 
Kinsbourne, M. (1980). Mapping a behavioral cerebral space. International Journal of Neuroscience, 11, 45-50.

Kowler, E., Anderson, E., Dosher, B., \& Blaser, E. (1995). The role of attention in the programming of saccades. Vision Research, 35, 1897-1916.

Lamb, M. R., Robertson, L. C., \& Knight, R. T. (1990). Component mechanisms underlying the processing of hierarchically organized patterns: Inferences from patients with unilateral cortical lesions. Journal of Experimental Psychology: Learning, Memory, \& Cognition, 16, 471-483.

Martin, M. (1979). Hemispheric specialization for local and global processing. Neuropsychologia, 17, 33-40.

Matin, E. (1974). Saccadic suppression: A review and an analysis. Psychological Bulletin, 81, 899-917.

Matin, E., Shao, K. C., \& Boff, K. R. (1993). Saccadic overhead: Information-processing time with and without saccades. Perception \& Psychophysics, 53, 372-380.

McConkie, G. W. (1991). Perceiving a stable visual world. In J. van Rensbergen, M. Deuijver, \& G. d'Ydewalle (Eds.), Proceedings of the Sixth European Conference on Eye Movements (pp. 5-7). Leuven, Belgium: Laboratory of Experimental Psychology.

McConkIE, G. W., \& RAYNER, K. (1976). Identifying the span of the effective stimulus in reading: Literature review and theories of reading. In H. Singer \& R. B. Ruddell (Eds.), Theoretical models and processes of reading (pp. 137-162). Newark, DE: International Reading Association.

NAvon, D. (1977). Forest before trees: The precedence of global features in visual perception. Cognitive Psychology, 9, 353-383.

Niemi, P., \& NÄÄtÄnen, R. (1981). Foreperiod and simple reaction time. Psychological Bulletin, 89, 133-162.

O’Regan, J. K., \& LeVy-Schoen, A. (1983). Integrating visual information from successive fixations: Does trans-saccadic fusion exist? Vision Research, 23, 765-768.

Pashler, H., Carrier, M., \& Hoffman, J. (1993). Saccadic eye movements and dual-task interference. Quarterly Journal of Experimental Psychology, 46A, 51-82.

Pollatsek, A., \& Rayner, K. (1992). What is integrated across fixations? In K. Rayner (Ed.), Eye movements and visual cognition: Scene perception and reading (pp. 166-191). New York: Springer-Verlag.

Pomerantz, J. R. (1983). Global and local precedence: Selective attention in form and motion perception. Journal of Experimental Psychology: General, 112, 516-540.

RAFAL, R., \& RoberTson, L. C. (1985). The neurology of visual attention. In M. Gazzaniga (Ed.), Handbook of cognitive neuroscience (pp. 159-188). Cambridge, MA: MIT Press.

RAYNER, K. (1978). Eye movements in reading and information processing. Psychological Bulletin, 85, 618-660.

RAYNER, K. (1998). Eye movements in reading and information processing: 20 years of research. Psychological Bulletin, 124, 372422.

Rayner, K., McConkie, G. W., \& Ehrlich, S. (1978). Eye movements and integrating information across fixations. Journal of Experimental Psychology: Human Perception \& Performance, 4, 529-544.

Rayner, K., \& Pollatsek, A. (1983). Is visual information integrated across saccades? Perception \& Psychophysics, 34, 39-48.

Robertson, L. C. (1996). Attentional persistence for features of hierarchical patterns. Journal of Experimental Psychology: General, 125, 227-249.

Robertson, L. C., Egly, R., Lamb, M. R., \& Kerth, L. (1993). Spatial attention and cueing to global and local levels of hierarchical structure. Journal of Experimental Psychology: Human Perception \& Performance, 19, 471-487.
Robertson, L. C., \& LAmb, M. R. (1991). Neuropsychological contributions to theories of part/whole organization. Cognitive Psychology, 23, 299-330.

Robertson, L. C., LAMb, M. R., \& ZAidel, E. (1993). Interhemispheric relations in processing hierarchical patterns: Evidence from normal and commissurotomized subjects. Neuropsychology, 7, 325-342.

Sanders, A. F., \& Houtmans, M. J. M. (1985). There is no central stimulus encoding during saccadic eye shifts: A case against general parallel processing notions. Acta Psychologica, 60, 323-328.

SAnders, A. F., \& Rath, A. M. (1991). Perceptual processing and speed-accuracy trade-off. Acta Psychologica, 77, 275-291.

ShePherd, M., Findlay, J., \& Hockey, R. (1986). The relationship between eye movements and spatial attention. Quarterly Journal of Experimental Psychology, 38A, 475-491.

vAN DuREN, L. (1993). Central stimulus processing during saccadic eye movements. In G. d'Ydewalle \& J. van Rensbergen (Eds.), Perception and cognition: Advances in eye-movement research (pp. 23-35). Amsterdam: North-Holland.

VAN KLEEK, M. (1989). Hemispheric differences in global versus local processing of hierarchical stimuli by normal subjects: New data and meta-analysis of previous studies. Neuropsychologia, 27, 1165-1178.

Volkmann, F. (1986). Human visual perception. Vision Research, 26, 1401-1416.

WARD, L. M. (1982). Determinants of attention to local and global features of visual forms. Journal of Experimental Psychology: Human Perception \& Performance, 8, 562-581.

Zuber, B., Crider, A., \& Stark, L. (1964). Saccadic suppression associated with microsaccades. Quarterly Progress Reports [Research Laboratory of Electronics, Massachusetts Institute of Technology], 74, 224-249.

Zuber, B., \& STARK, L. (1966). Saccadic suppression: Elevation of visual threshold associated with saccadic eye movements. Experimental Neurology, 16, 65-79.

\section{NOTES}

1. To avoid confusion on this point, we characterize the use of attention by voluntary saccades as involuntary, because attention moves to saccade targets even if subjects try to attend to a different region of a visual display away from the saccade target (e.g., Deubel \& Schneider, 1996; Hoffman \& Subramaniam, 1995; Irwin \& Gordon, 1998). Even though executing a saccade is a voluntary act, the way attention is engaged by the saccade is not under volitional control.

2. Ward's (1982) figures were different from those illustrated in Figure 1 and described by this text. They were, however, hierarchical in the same sense.

3. It is interesting that saccade latencies differed with respect to saccade direction. Differences in the physical/motor characteristics of rightward and leftward saccades, such as velocity, were not observed. Saccade latency, however, is also affected by the salience or discriminability of the saccade target. Although the same apparatus was used for rightward-saccade subjects and leftward-saccade subjects, the room in which the two groups were tested was different. Subtle changes in the environmental lighting may have changed the luminance of the display slightly, so that the target was more difficult to perceive for the subjects in the rightward-saccade condition.

4. The results of Experiment 2 could arise if the simple change in spatial location of the stimuli, independent of saccades, interferes with the global-local attention shift. However, Robertson (1996) demonstrated no effect of changing stimulus location on this task when the eyes remain at constant fixation. 


\section{APPENDIX}

There is a disadvantage to using ANOVA models to estimate the point at which the RT2 curve reaches an asymptote, in that the estimates are restricted to RSI values that were chosen a priori. The true estimate for the time required to complete global-local shifts of attention, however, is likely to fall between the selected RSI values. One way to address this limitation is to use linear spline regression analyses.

Spline regression fits continuous piecewise functions to data. Rather than observing a single linear trend throughout the entire data space, this procedure allows many linear trends to be observed by dividing the data space into segments. Segment boundaries are defined by the joints of the piecewise function. To find appropriate segment boundaries, the $x$ values of the joints are systematically chosen. For each selection, a set of linear functions that minimizes the error in prediction across the whole of the data space is calculated. The best-fitting piecewise function yields the smallest error term. In order to assess specific hypotheses with spline regression, various functions within the piecewise set can also be defined a priori. For example, between certain joints, the function can be defined to be a horizontal line.

This procedure was used to estimate the point at which the RT2 curve reached asymptote. Because we used spline regression to fit linear functions to curvilinear data, RT2 scores were first logarithmically transformed, since this procedure tends to linearize nonlinear data patterns. Two-part piecewise functions with the following form were fit to the data:

$$
f(x)=\left\{\begin{array}{cc}
m x+b & \text { if } x<x^{\prime} \\
c & \text { if } x \geq x^{\prime},
\end{array}\right.
$$

where $x^{\prime}$ defines the joint of the piecewise function and $c$ is a constant defined by the value of $f\left(x^{\prime}\right)$ :

$$
c=m x^{\prime}+b .
$$

Phrased in terms of the experimentaldesign, $x^{\prime}$ is the point at which RT2 no longer differs by RSI. When RSI is less than $x^{\prime}$, the spline regression procedure calculates the best-fitting regression line for the RT2 data; however, for RSIs greater than $x^{\prime}$, the RT2 data trend is considered to be a horizontalline. In 5msec intervals, all values of $x^{\prime}$ were selected from between 300 and $450 \mathrm{msec}$. The overall piecewise function that minimized the mean-square error in prediction was accepted, and the value of $x^{\prime}$ for that function was interpreted as the estimated time required to shift global-local attention. Spline regression analyses determined that the estimated time to shift global-local attention was $390 \mathrm{msec}$.

(Manuscript received June 1, 2000;

revision accepted for publication October 24, 2001.) 